www.jmscr.igmpublication.org

Impact Factor 5.84

Index Copernicus Value: 83.27

ISSN (e)-2347-176x ISSN (p) 2455-0450

crossref DOI: _https://dx.doi.org/10.18535/jmscr/v5i8.37

Journal Of Medical Science And Clinical Research

\title{
Evaluation of Method for Glycated Hemoglobin and Its Correlation with Microalbuminuria as Early Markers of Nephropathy in Type II Diabetes Mellitus
}

\author{
Authors \\ Khadija Umar Abdullahi,*Uma Arora, Ravjit Sabharwal \\ Panjab Institute of Medical Sciences Jalandhar \\ *Corresponding Author \\ Dr Uma Arora \\ Professor Biochemistry PIMS Jalandhar \\ Email: umaarora_15@Yahoo.co.in
}

\begin{abstract}
Diabetic nephropathy is the leading cause of end stage renal disease and mortality. The aim of the study was (i) to correlate between two methods of HbAlc estimation; the column chromatography and the immunoturbidimetric method and (ii) to evaluate microalbuminuria and glycated hemoglobin (HbAlc) as early risk markers of nephropathy in type II diabetes mellitus. The present study includes two parts; the first part consists of forty known diabetic patients in which the method comparison of HbAlc was studied. The second part of the study comprises of eighty-four known diabetic patients and thirty healthy control subjects in which the presence of HbAlc and microalbumin was estimated and correlated. Venous blood was obtained for HbAlc \& plasma glucose for the first part of the study. For the second part, venous blood was obtained for $\mathrm{HbAlc}$, and blood glucose, while their morning urine sample was obtained for detection of microalbuminuria. Statistical analysis was done using SPSS version 24. All p-values $<0.05$ were considered statistically significant. The two HbAlc methods were highly correlated ( $r=0.905)$. However, the mean of immunoturbidimetric method is slightly lower (5.23\%) when compared with column chromatographic method (5.69\%).Both the methods had good correlation with random blood sugar value. Random Blood Sugar (RBS),

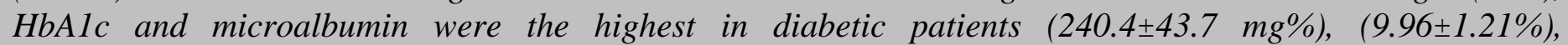
and $(108.5 \pm 36.2 \mathrm{mg} \%)$ when compared with non-diabetic healthy control subjects $(93.4 \pm 16.1 \mathrm{mg} \%)$, $(4.80 \pm 0.50 \%)$ and $(8.1 \pm 2.4 \mathrm{mg} \%)$ respectively. Microalbuminuria and HbAlc had a significant correlation $(r=0.626, p<0.01)$. Microalbuminuria also had a good correlation with duration of diabetes $(0.764, p<0.01)$. Keywords: Random Blood Sugar--RBS, Glycated Hemoglobin---HbAlc, Microalbumin, Nephropathy, Diabetes Mellitus(DM).
\end{abstract}

\section{Introduction}

Diabetes is a common endocrine disorder, characterized by persistent hyperglycemia as a result of inadequate insulin and/or insulin resistance $^{(1)}$. Untreated hyperglycemia can cause a lot of complications like neuropathy, nephropathy and retinopathy. Insulin resistance is characterized by a subnormal response to a given concentration of insulin and can be measured indirectly by a fasting insulin level: the increased levels of insulin correspond to higher degrees of insulin resistance ${ }^{(2)}$. 
Diabetic nephropathy is a long term complication of (diabetes mellitus) DM and is the chief cause of morbidity and premature mortality. The pathophysiologic basis for elevated urinary albumin excretion entails the binding of glucose to proteins resulting in excessive protein glycosylation with the buildup of advanced glycated end products. This leads to the deposition of advanced glycated end product on the glomerulus resulting in renal and glomerular hypertrophy, mesangial matrix accumulation and thickening of glomerular basement membrane. This abnormality permits the leakage of low molecular weight proteins like albumin ${ }^{(3)}$

Glycated hemoglobin (HbA1c) is the presence of carbohydrate-protein linkage on the N-terminus of the $\beta$-chains of hemoglobin, predominantly $\mathrm{HbA}$ in adults ${ }^{(4)}$. The percentage of glycated hemoglobin in the plasma of a patient provides an estimate of blood glucose levels over a period of 120 days ${ }^{(5)}$.

Microalbuminuria is defined as Urinary albumin excretion between $30-300 \mathrm{mg} /$ day. In the early stages of the disease, there is an increase in urinary albumin excretion, which progresses to overt albuminuria and then to renal failure ${ }^{(6)}$.

In type II diabetic patients, the duration of diabetes and elevated glycated hemoglobin (HbA1c) value, predicted increased microalbumin excretion rate. As determination of microalbumin level in urine is an easy method of screening the diabetic patients, it may be useful to prevent the onset of future renal disease. A good glycemic control in the early stages reduces chances of microalbuminuria ${ }^{(7)}$.

\section{Material and Methods}

Forty patients who had been diagnosed with type II diabetes mellitus with duration of more than one year were included in the study. The patients were receiving treatment and counselling on monthly basis at the diabetic clinic of Hospital. Their fasting blood glucose was being measured once in a month while HbA1c was checked once every three months. Informed consent was taken from the patients before including them into the study. Another group consisting of eighty-four known diabetic patients (56 females and 28 males), admitted as inpatients and attending outpatient clinics of the hospital, were also included in the present study. Thirty healthy subjects were included in the control group.

\section{Inclusion criteria}

Known diabetic patients, aged between 35 to 90 years, of either sex, were chosen for the study.

\section{Exclusion criteria}

Diabetic patients who had macroalbuminuria were excluded from the study. Patients with mental illness or suffering from serious medical conditions like jaundice, anemia etc, were excluded.

A structured questionaire regarding the demographic data such as name, age, sex, duration of diabetes, presence or absence of hypertension, smoking habit was recorded from each patient.

The blood samples $(1 \mathrm{ml})$ were collected by the technicians at the Central Blood Collection Centre from patients, in EDTA containers for $\mathrm{HbA1c}$ and in oxalate and fluoride vials for glucose. The samples were sent to laboratory to measure HbA1c with column chromatography and immunoturbidimetric methods. The blood samples for $\mathrm{HbA} 1 \mathrm{c}$ were kept in refrigerator $\left(4^{\circ} \mathrm{C}\right)$ until analyzed. Blood sample was analyzed for blood glucose using GOD-POD method. For microalbumin estimation, morning urine sample was taken. All urine samples were tested for the presence of albumin by pyrogallol red method.

\section{Statistical analysis}

All statistics in the study was performed using SPSS statistical software version 24

\section{Results}

A total of 40 samples were analyzed for HbA1c estimation. The mean age of the patients included in the study was $41.48 \pm 11.4$ years (range 2548years). There were 32 (80\%) females and 8 (20\%) males. A comparison was made between two methods available in the laboratory for the estimation of HbA1c.. The results for both the techniques are shown in table1. The mean $\mathrm{HbA} 1 \mathrm{c}$ 
was slightly lower for immunoturbidimetric (5.23\%) method than column chromatography (5.69\%). The correlation analysis was also done between the results obtained by column chromatography and immunoturbidimetric method (Fig1) The correlation coefficient was found to be 0.905. The result showed a good correlation between both methods. A good correlation was observed between RBS \& HbA1c by both the methods used in study. HbA1c value by Column chromatographic method and RBS had correlation coefficient of 0.70 and $\mathrm{HbA1c}$ value by immunoturbidimetric method and RBS had correlation coefficient of 0.78 (Table 11)

In the second part of the study on type II diabetic patients, microalbumin was estimated in all the diabetic and control cases in the spot urine sample. $\mathrm{HbA} 1 \mathrm{c}$ and random blood sugar was also estimated for these subjects.

Eighty-four type II diabetes mellitus patients aged between 35-90 years were selected for this cross sectional study. The mean age of the patients were 58.64 years, out of which $56(66.6 \%)$ were females and $28(33.3 \%)$ males.

The value of Random blood sugar,HbA1c and Microalbumin was compared between diabetic cases and non diabetic healthy controls (Table 111). The RBS for Diabetic group was $240.40+/-$ $43.70 \mathrm{mg} \%$ compared to $93.4+/-16.1 \mathrm{mg} \%$ for controls.HbA1c was $9.96+/-1.21 \%$ in diabetics compared to $4.8+/-0.5 \%$ for controls and Microalbumin was $108.5+/-36.22 \mathrm{mg} \%$ in diabetic group compared to $8.1+/-2.4 \mathrm{mg} \%$ in controls. All the results were statistically significant.

Microalbumin level in relation to duration of Type 11 diabetes was also compared. Its level was observed to be higher in diabetic subjects with duration of diabetes more than 10 years.(Table $1 \mathrm{~V})$.There was also good correlation between microalbumin and duration of diabetes $(r=0.764$, $\mathrm{p}<0.01)($ Graph 2)

A correlation was also observed between microalbumin and HbA1c level in Type 11 diabetic patients $(\mathrm{r}=0.626, \mathrm{p}<.001)($ Fig.3)
The result of the study shows that poor glycemic control was associated with higher proportion of microalbuminuria. Sixty of the cases i.e (71.4\%) with poor glycemic control had microalbuminuria. The difference was statistically significant $(\mathrm{P}<0.001)$.

There was significant sex predominance, as $66.6 \%$ of females were found to have microalbuminuria compared to $33.3 \%$ of males $(\mathrm{p}=0.701)$.

Table 1: Comparison between column chromategraphy and immunoturbidimetric method.

\begin{tabular}{|l|c|}
\hline HbA1c (\%) & Mean \pm SD \\
\hline Column chromatography & $5.69 \pm 1.99$ \\
\hline Immunoturbidimetry & $5.23 \pm 1.95$ \\
\hline
\end{tabular}

Table 11 : Correlation of HbA1c with RBS

\begin{tabular}{|l|c|c|} 
Method & RBS $(\mathrm{mg} \%)$ & HbA1c (\%) \\
\hline Columnchromatography & $119.7 \pm 30.2$ & $5.69 \pm 1.99$ \\
\hline Immunoturbidimetry & $119.7 \pm 30.2$ & $5.23 \pm 1.95$ \\
\hline
\end{tabular}

Table 111--Mean level of biochemical parameters in controls and Type 11 Diabetic patients

\begin{tabular}{|l|c|c|c|}
\hline Parameter & Controls & $\begin{array}{c}\text { Diabetic } \\
\text { cases }\end{array}$ & P value \\
\hline RBS(mg\%) & $93.1+/-$ & $240.4+/-$ & $<0.001$ \\
& 16.1 & 43.7 & \\
\hline HbA1c(\%) & $4.30+/-$ & $9.96+/-$ & $<0.001$ \\
& 1.21 & 1.21 & \\
\hline Microalbumin(mg\%) & $8.10+/-$ & $108.5+/-$ & $<0.001$ \\
& 2,4 & 36.22 & \\
\hline
\end{tabular}

Table 1V----Microalbumin in relation to duration of diabetes (in years)

\begin{tabular}{|c|c|c|}
\hline $\begin{array}{l}\text { Duration of } \\
\text { Diabetic in } \\
\text { years }\end{array}$ & $\begin{array}{l}\text { Microalbumin(mg/dl)Mean+/- } \\
\text { S.D }\end{array}$ & value \\
\hline $1-------4$ & $25.5+/-10.9$ & $<0.001$ \\
\hline $5-----10$ & $82.7+/-26.9$ & $<0.001$ \\
\hline$>10$ years & $187.5+/-36.7$ & $<0.001$ \\
\hline
\end{tabular}



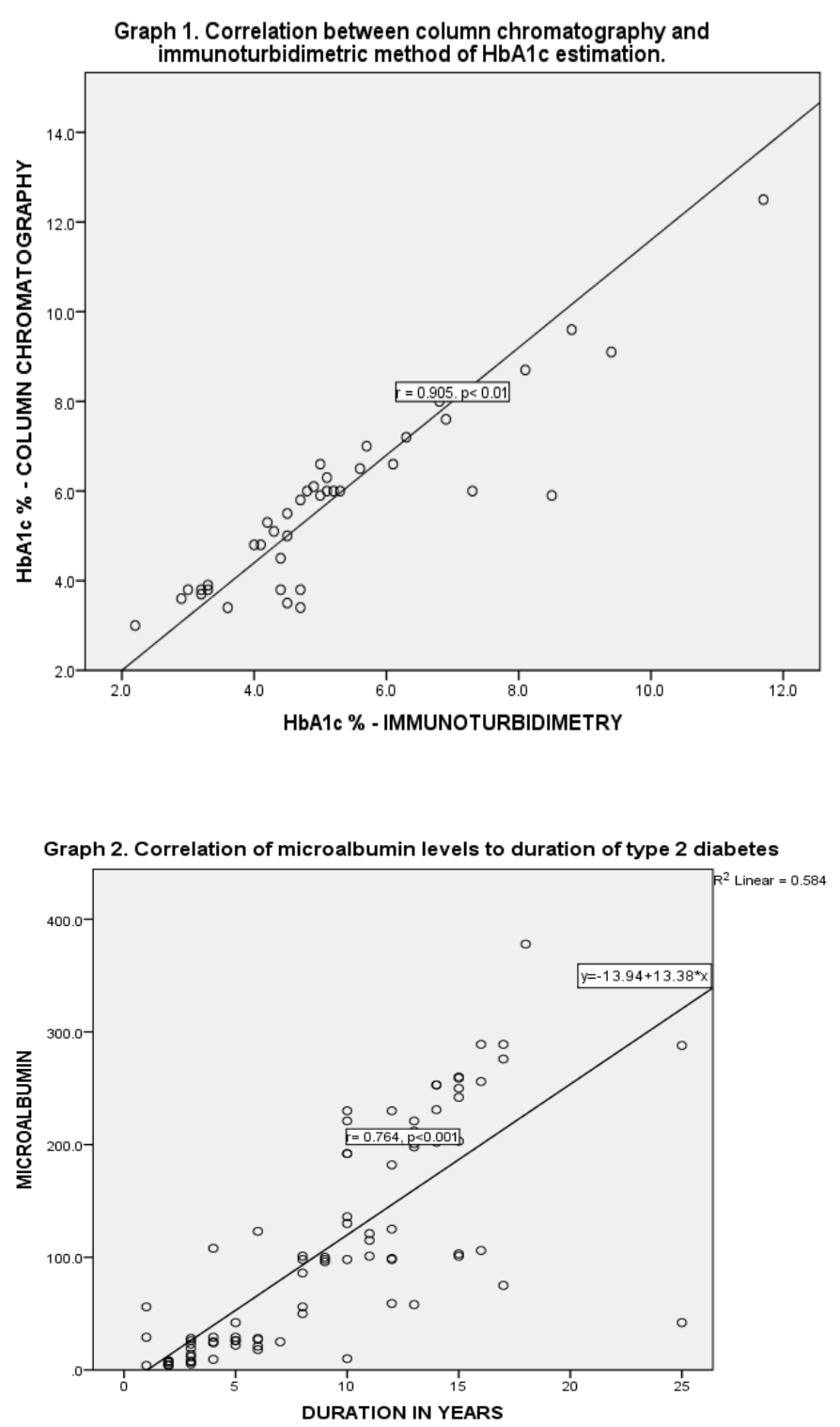

Graph 3: Correlation of microalbumin levels to HbA1c in diabetic cases

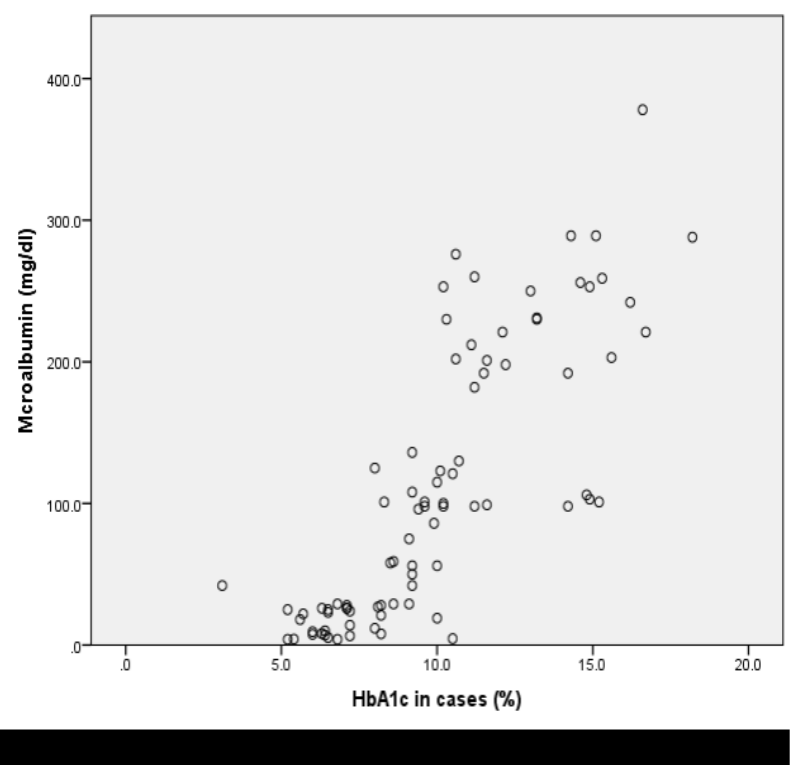

\section{Discussion}

The prevalence of diabetes is increasing worldwide at an alarming rate. The patient's longterm glycemia is associated with various complications ${ }^{(8)}$ and can be measured using glycated hemoglobin ${ }^{(9)}$. Therefore, glycated hemoglobin measurement by laboratories should be precise and accurate. When glycated hemoglobin was measured by different methods, important differences were observed ${ }^{(10)}$

In the present study, it was found that the two methods are strongly correlated. The correlation coefficient r; was 0.905(Fig1). However, immonuturibidimetric method has lower mean of HbA1c (5.23 $\pm 1.95 \%)$ compared to column chromatography $\quad(5.65 \pm 1.99 \%)$ (Table1). Since immunoturbidimetric method was faster and easier to handle, it was chosen for further study.

Harris et. al (2003) compared four points -of -care methods with the Roche tinaqant and obtained the Pearson correlation of over 0.9 for all the four methods: DCA 2000, Nycocard, Diastat and D55. Diastat and DCA 2000 showed the best function among all the four methods. It was concluded that these two methods can be an appropriate replacement for each other, and also for the Roche method $^{(11)}$.

The first noticeable sign of diabetic renal disease is the presence of microalbuminuria ${ }^{(12)}$, the early detection and intervention of which can delay the onset of overt nephropathy in diabetic patients ${ }^{(13)}$. In order to prevent the development of microalbuminuria, blood pressure should be maintained at less than $130 / 80 \mathrm{mmHg}$ and glycemic control (HbA1c) should be maintained below $7 \%$. HbA1c level is an important factor in the transition from normoalbuminuria to microalbuminuria and then to overt diabetic nephropathy ${ }^{(14)}$. Diabetic nephropathy has been linked to elevated levels of advanced glycation end products ${ }^{(15)}$.

The present study was conducted on 84 diabetic patients. Age of patients in this study ranged between 35-90 years with the mean of 58.64 years. A similar mean age was observed in several 
studies by Chowta et.al (2009) \& Mohammad et.al $(2012)^{(14,15)}$.

In the present study values of Random blood sugar,HbA1c and microalbumin were higher in diabetic patients compared to controls(Table 111)There was also observed correlation between microalbuminuria and duration of diabetes (Table 1V). A correlation was also observed between $\mathrm{HbA1c}$ and microalbuminuria in diabetic patients. (Fig 111).Similar results have been reported byVarghese et al(2001). A good glycemic control in early stages can reduce chances of microalbuminuria ${ }^{(7)}$. A good glycemic control in early stages reduces chances of microalbuminuria. It was found that sixty out of 84 diabetic patients (71.4\%) had early nephropathy. The result is found to be low compared to other studies. A study by Omar et. al (2015) showed that 31 out of $40 \quad(77.5 \%)$ diabetic patients had early nephropathy ${ }^{(16)}$. Other results were found to be higher than those reported by American Diabetes Association (ADA) $(20-40 \%)^{(17)}$.

In another study, it was shown that $82.7 \%$ had poor glycemic control; however, there was no correlation between $\mathrm{HbAlc}$ and microalbuminuria) ${ }^{(18)}$. A study by Vanelli et. al (2005), it was reported that higher HbA1c was associated with increasing $\operatorname{age}^{(19)}$. Difference in ethnic susceptibility to nephropathy might be the likely reason for this variation.

Being a developing country, there is a great need that microalbumin and $\mathrm{HbA} 1 \mathrm{c}$ testing should be done in both, newly diagnosed as well as already diagnosed type II diabetic patients as early markers of nephropathy. This is because the prevalence of microalbuminuria in diabetic patients is found to be high. Therefore, patients and physicians should give very high priority to improving glycemic control sufficiently to maintain glycated hemoglobin values below $7 \%$. If this can be achieved, the number of patients in whom microalbuminuria develops would decline substantially, and in turn, lower the number of patients who develop end-stage renal disease.

\section{Conclusion}

In the present study, two methods for estimating glycated hemoglobin were compared and relationship between microalbumin and glycated hemoglobin with duration of diabetes was evaluated.

- The present study was divided into two parts.

- In the first part of the study, a comparison was made between two methods available in the laboratory (immunoturbidimetric and column chromatography) for the estimation of $\mathrm{HbA} 1 \mathrm{c}$. The mean $\mathrm{HbA} 1 \mathrm{c}$ was slightly lower for immunoturbidimetric $(5.23 \%)$ method than column chromatography (5.60\%) (Table 1).Correlation analysis between two methods was also made. The correlation coefficient was found to be 0.905 suggesting a good correlation between two methods (Graph 1).

- Correlation analysis between column chromatography and RBS and between immunoturbidimetric method and RBS was also done. The correlation coefficient was found to be 0.70 and 0.78 for the two methods suggesting a good correlation between HbA1c and RBS value for both the methods. In the second part of the study, 84 patients aged between 35 to 90 suffering from type II diabetes were selected along with 30 controls.

- HbA1c, random blood sugar and urinary microalbumin was estimated in these Diabetic patients and in controls.

- Levels of RBS, microalbumin, HbA1c were found to be higher in diabetic cases compared with controls $(\mathrm{p}<0.001)$ (Table 111).

- Microalbumin level in relation to duration of type II diabetes was also compared. Its level was observed to be higher in diabetic subjects with duration of diabetes more than 10 years (Table $1 \mathrm{~V}$ ) and there was good correlation between microalbumin 
and duration of diabetes $(\mathrm{r}=0.764)$ (Graph 2).

- A correlation was also observed between microalbumin and $\mathrm{HbAlc}$ in type II diabetic patients ( $\mathrm{r}=0.626$, Graph 3 ).

- Microalbumin was found to be higher in Diabetic cases $(71.4 \%)$ compared with those having poor glycemic control $(28.5 \%)$.

\section{References}

1. Zhaolan Liu, Chaowei Fu, Weibing Wang, Biao Xu. Prevalence of chronic complications of type 2 diabetes mellitus in outpatients - a cross sectional hospital based survey in urban China, Health and Quality of Life outcomes 2010; (1):62-68.

2. Wallace TM, Matchews DR. The assessment of insulin resistance in man. Diabet Med. 2002; 19:527-534. Doi : 10. 10461j. 1464-5491. 00745.

3. Mason RM, Wahab NA. Extracellular matrix metabolism in diabetic nephropathy. J Am Soc Nephrol 2003; 14(2): 1358-1373.

4. John WG, Bullock DG, Mackenzie F. Methods for the analysis of glycated hemoglobins. What is being measured? Diabetic Med 1992; 9(1):15-19.

5. Tran HD, Hofer TL, Lee T, Cembrowski GS. Unique approach to derivation of random error in laboratory assays: application to glycohemoglobin testing demonstrates poor clinical performance for immunochemistry assay. Diabetes Technol Ther. 2003; 5:975-978. Doi:10.1089/152091503322641015.

6. Mogensen CE, Christensen CK, Vittinghus E. The stages in diabetic renal disease: with emphasis on the stage of incipient diabetic nephropathy. Diabetes 1983; 32(2) :64-78.

7. A Varghese, R Deepa, M Rema, V Mohan. Prevalence of microalbuminuria in type 2 diabetes mellitus centre in southern India. Postgrad Med J 2001; 77(1) :399-402.

8. Goldberg RB, Mather K. Targeting the consequences of the metabolic syndrome in the diabetes prevention program. Arterioscler Thromb Vasc Biol. 2012, 32(2):2077-2082.

9. Bryskiewicz ME, Majkowska L. Aspects of the standardization of $\mathrm{HbA1c}$ measurement. Pol Merker Lekarski. 2011; 30(4):155-159.

10. Hoezel W, WeyKampC, Jeppson JO, Miedema K, Barr JR, Goodall I, Hoshino T, John WG, Kobold U, Little R, Mosca A, Mauri P, Paroni R, Susanto F, TAku I, Thienpont L, UmemptoM, Wiedmeyer HM. IFCC reference system for measurement of $\mathrm{HbA} 1 \mathrm{c}$ in human blood and national standardization schemes in the United States, Japan and Sweden: a method-comparison study. Clin Chem. 2004; 50(2): 166-174.

11. Harris SB, Petrella RJ, Leadbetter W. Lifestyle interventions for type 2 Diabetes Mellitus. Relevance for clinical practice. Can Fam physician. 2003; 49(4); 16181625. PMid: 14708927, PMCid:2214163.

12. Moore DJ, Gregory JM, Kumali-crystal YA, Simmons JH. Mitigating micro-and macrovascular complications of diabetes beginning in adolescence. Vasc Health Risk Manga 2009; 5(1):1015-1031.

13. Spanou E, Krantzis I, Iatrou C. Microalbuminuria and diabetic nephropathy: epidemiology, prognostic significance and prevention. Archives of Hellenic Medicine 2009; 26(3): 316-330.

14. Chowta Nk, Pant P. Chowta Mn. Microalbuminuria in diabetes mellitus: association with age, sex, weight and creatinine clearance. Indian J Nephrol 2009; 19 (2): 53-56.

15. Mohammad HA, Fargaly HS, Metwalley KA, Monazea EM, Abd El HAfeez HA. Predictors of glycemic control in children 
with type 1 diabetes mellitus in AssiutEgypt. Indian J Endocrino Metab 2012; 16(1):796-802.

16. OmarA,Magdy;Moustafa,M.Ezk;Ahmed,A .Eikafoury;Marwa,S.Kandil.Microalbumin uria with Type 1 Diabetes Mellitus. Alexandria journal of Medicine. (2015)51,83-88

17. American Diabetes Association.Standards of Medical care in diabetes.Diabetic Care 2012;35(supp:1):11-63.

18. Maskari FA, Sadig ME, Obinecho E. Prevalence and determinants of microalbuminuria among diabetic patterns in the United Arab Emirates. BMC Nephrology. 2008; 9(1). Available from: http://www.biomedcentral.com/14712369/9/1.

19. Vanelli M ;Cerutti F;Lorini R;Meschi $\mathrm{F} ; \mathrm{MCDC}$ - Italy group.Nationwide cross sectional survey of 3560 children and adolescents with diabetes in Italy.Journal of Endocrinological investigations 2005,28:692-699. 